\title{
Nanocrystalline Anatase Titania Thin Films Synthesized by Spray Pyrolysis for Gas Detection
}

\author{
M.Z. Obida ${ }^{1}$,H.H. Afify ${ }^{1}$, M.O. Abou-Helal ${ }^{1}$, and H.A.H. Zaid ${ }^{2}$ \\ ${ }^{1}$ Physics Dept., Solid State Division, National Research Center NRC, \\ 12622 Dokki, Cairo, Egypt. \\ ${ }^{2}$ Physics Dept., Science, Arts and Education Faculty of Girls, \\ Ain-Shams Uni., Heliopolis, Cairo, Egypt.
}

Nanocrystalline (NC) materials are exhibiting small particle size and large surface area which may be applied for gas sensors. Nano-crystalline $\mathrm{TiO}_{2}$ films are synthesized by spray pyrolysis technique. The XRD investigation for the deposited films shows that they have only polycrystalline anatase phase with nano-size. The AFM photographs reveal the nano-size of the constituents. The crystallite size and crystallinity of the samples are discussed with respect to the film thickness and deposition temperature. The dc resistivity dependence on temperature for samples is studied and correlated with the preparation parameters. The sample resistance is measured in the presence of technologically important gases $\mathrm{CO}, \mathrm{O}_{2}$ and $\mathrm{H}_{2}$. The sensitivity and response time of the samples to the tested gases are assigned at varied operating temperature. It is found that optimum operating temperature for $\mathrm{H}_{2}$ and $\mathrm{CO}$ is $330^{\circ} \mathrm{C}$ and $310^{\circ} \mathrm{C}$, respectively. Also, the maximum sensitivity is $90 \%$ and $70 \%$, and the response time is about 8 and 3 seconds for $\mathrm{H}_{2}$ and $\mathrm{CO}$ respectively, at the proceeding operating temperature.

\section{Introduction:}

Nano-crystalline materials with particle size smaller than $100 \mathrm{~nm}$ exhibit amazing properties which are not found in conventional materials [1]. One of the distinctive features, the main one for gas sensors, is an extremely large specific surface area. Oxide semiconductor films are promising for gas sensors due to the dependence of their electrical conductivity on the environmental gases such as $\mathrm{O}_{2}, \mathrm{CO}, \mathrm{H}_{2} \ldots \ldots$. [2].

Titanium dioxide is being used in a great variety of applications. It has been investigated for humidity and gas-sensing behavior $[3,4]$. It has three 
different crystallographic forms: brookite, anatase and rutile. Anatase is metastable and converted irreversibly into rutile at high temperature. Its preparation is fundamental to obtain properties suitable for gas-sensing applications such as: structural stability, porosity and high surface-to-volume ratio in order to emphasize surface effects. The sensing properties of $\mathrm{TiO}_{2}$ films are based on surface interactions of reducing or oxidizing species, which affect the conductivity of the films.

Films of nano-sized $\mathrm{TiO}_{2}$ could be achieved by different techniques such as sputtering in reactive atmosphere followed by thermal annealing at $800^{\circ} \mathrm{C}$, Sol-Gel, Spray Pyrolysis, Screen Printing, Laser Ablation, .... etc. The main purpose of this paper is to prepare low cost nano-sized $\mathrm{TiO}_{2}$ films with structural and electrical characteristics suitable for sensing oxidizing and reducing gases.

\section{Experimental:}

A developed spray pyrolysis setup has been designed and assembled to overcome limitations of previous systems such as repeatability and homogeneity of the deposited films. The system is almost fully computerized and consists of the following components: PC-controlled $x-y$ table, digital temperature controller, digital gas flow meter and digital solution pump. Most of these components are working alone with built in processors, and/or are controlled by PC. A schematic diagram of the used system is given in Fig (1).

The $\mathrm{TiO}_{2}$ films were deposited on $2.5 \times 1.5 \times 0.1 \mathrm{~cm}^{3}$ glass substrates, after applying the conventional cleaning procedures. This type of glass (Menzel-Gläser, Germany) is stable till more than $600^{\circ} \mathrm{C}$. It has a lower cut off wavelength $(\approx 280 \mathrm{~nm})$, which far away from that of the prepared $\mathrm{TiO}_{2}(\approx 325$ $\mathrm{nm})$, and also it is not expensive which makes the produced films more attractive for industrial applications. The deposition parameters are: $0.8 \mathrm{M}$ solution composed of chemically pure $\mathrm{TiCl}_{4}$ dissolved in ethanol. Filtered air is used as a carrier. The solution and gas flow rates are $0.7 \mathrm{ml} / \mathrm{hr}$ and $25 \mathrm{1} / \mathrm{hr}$, respectively, the substrate temperature range is $325-475^{\circ} \mathrm{C}$ and the spray time range is $5-30$ minutes. 


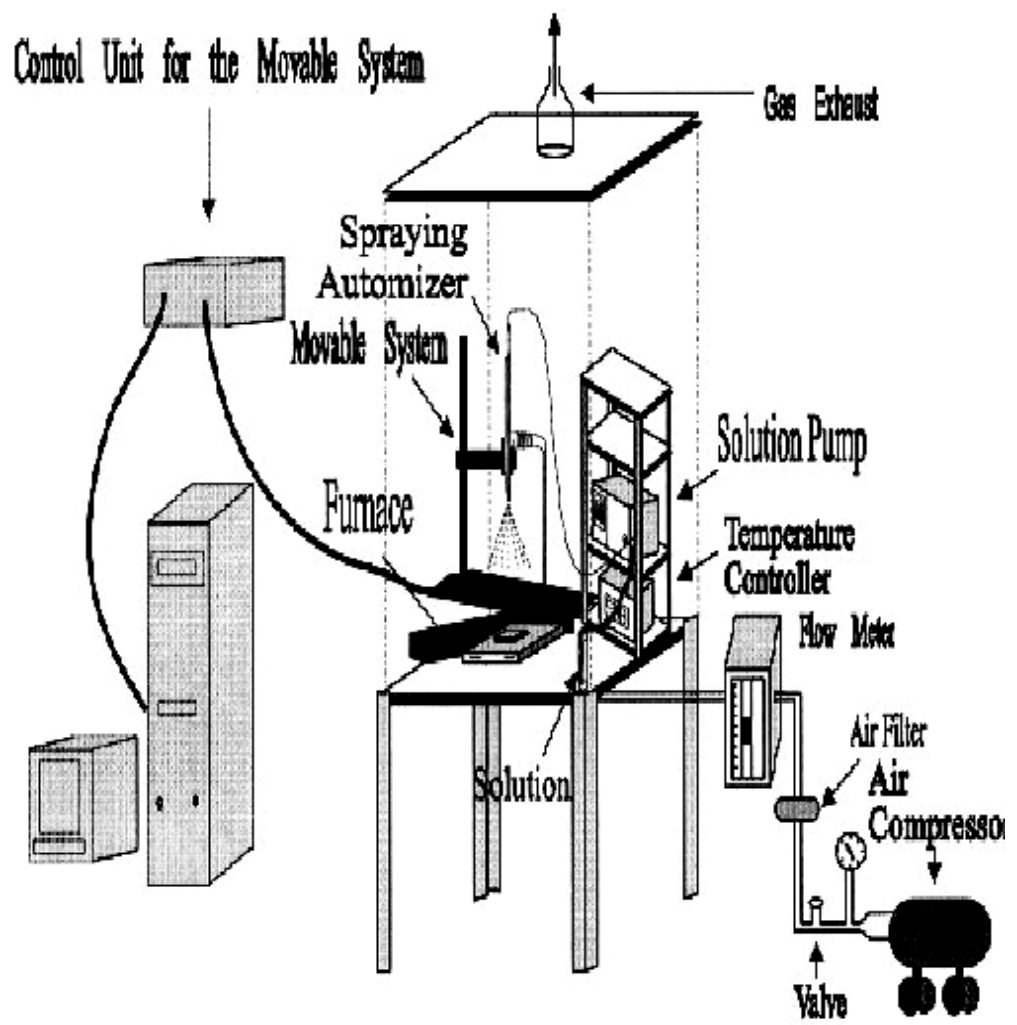

Fig. (1): The movable and computerized spray pyrolysis system with $X-Y$ table.

$\mathrm{X}$-ray diffraction was used to elucidate the structure of the prepared films. The as-deposited films were subjected to structural analysis using (Diano corroboration-USA equipment with $\mathrm{CO} \mathrm{k}_{\alpha}$ radiation). The diffraction patterns were recorded automatically with a scanning speed $8 \mathrm{deg} / \mathrm{min}$ and scanning angular range $\left(2 \theta=4^{\circ}\right.$ to $\left.90^{\circ}\right), \lambda=1.514184(\AA)$. The atomic force microscope (AFM) studies are carried out in the National Institute of Standards (Egypt). The deposited samples are imaged in contact mode. The images presented here are submitted to a flatness process. The crystallite diameter is measured on the original image before the flatness process. The film thickness is measured in the National Institute of Standards by Interference Microscope for samples have an edge and coated with Ag film. The gas sensing properties of the deposited films toward oxygen, hydrogen and carbon monoxide (CO) are measured at controlled humidity (RH 35\%) and the temperature of the chamber containing the sensor was maintained at the operating temperature. The changes in the sensor electrical resistance due to variations of the surrounding atmosphere have been recorded and monitored by METEX (PC interface Multimeter Peak Tech 4370). Dry carbon monoxide gas generation system was made to obtain CO gas 
from chemical reaction of sodium formate $(\mathrm{NaCOOH}$, Fine chem. LTD) and sulphuric acid $\left(\mathrm{H}_{2} \mathrm{SO}_{4}, 98 \%\right)$. The produced $\mathrm{CO}$ volume is determined from the following equation:

$$
2 \mathrm{NaCOOH}+\mathrm{H}_{2} \mathrm{SO}_{4} \rightarrow \mathrm{Na}_{2} \mathrm{SO}_{4}+2 \mathrm{CO} \uparrow+2 \mathrm{H}_{2} \mathrm{O}
$$

The other two gases $\left(\mathrm{O}_{2} \& \mathrm{H}_{2}\right)$ are fed from their corresponding cylinders.

\section{Results and Discussion:}

\subsection{Film Structure}

The X-Ray diffraction (XRD) analysis is conducted to determine the phases and the grain size. The XRD patterns for the investigated samples prepared at different deposition temperatures and constant deposition time as well as those deposited at different deposition times and constant deposition temperature are shown in Fig. $(2 \mathrm{a}, \mathrm{b})$.

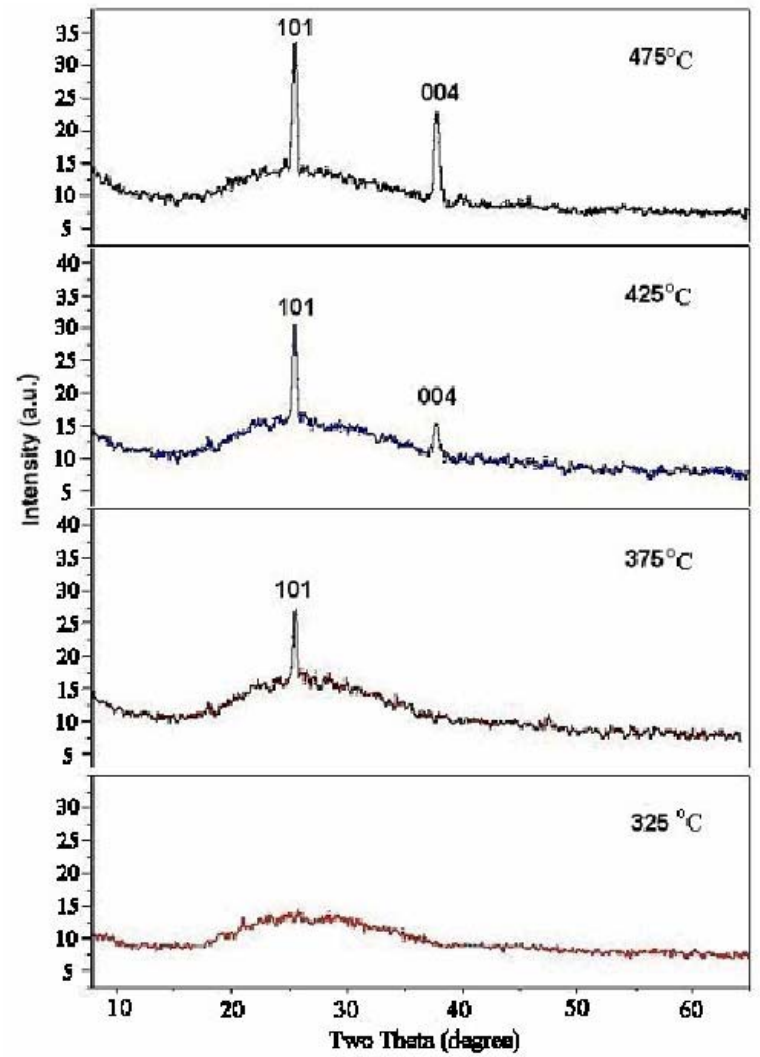

Fig. (2a): $\mathrm{XRD}$ of $\mathrm{TiO}_{2}$ films deposited at different deposition temperature and $30 \mathrm{~min}$ spray time. 


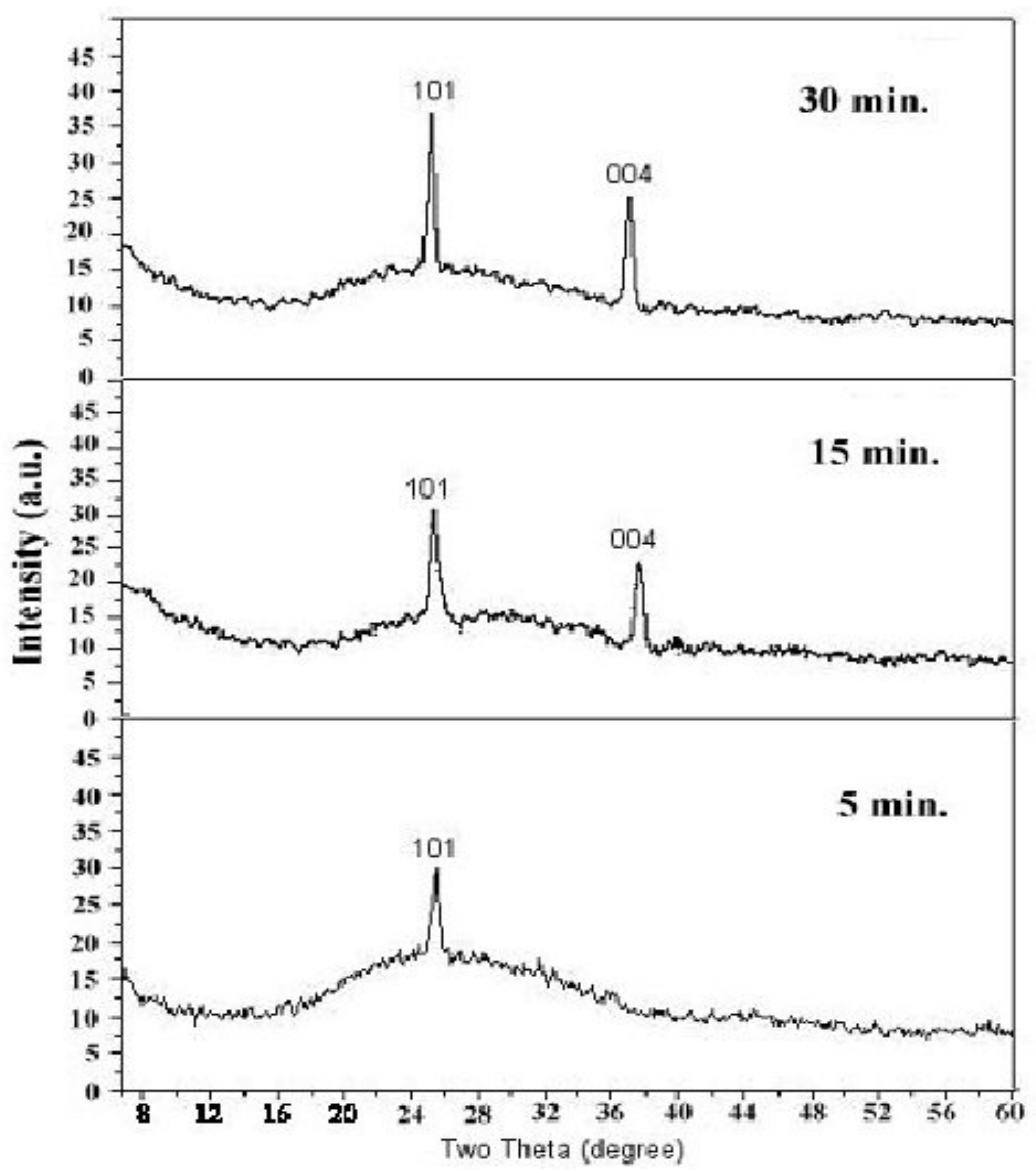

Fig. (2b): XRD patterns of $\mathrm{TiO}_{2}$ thin films deposited at constant substrate temperature $\left(500^{\circ} \mathrm{C}\right)$ and different deposition time.

It is clear that the samples deposited at $325^{\circ} \mathrm{C}$ shows a broad hump at $2 \theta$ (20-30), which indicating the amorphous structure. In order to have a clear cut decision GIXRD and/or ED has to be used, unfortunately, we do not have either facilities. The XRD patterns for samples prepared at temperatures $>$ $325^{\circ} \mathrm{C}$ show only two peaks, their intensities increase as the deposition temperature and time increase. These peaks are indexed with the standard JCPDS (21-1272) and found to be corresponding to (101) and (004) anatase phase [5-7]. The phase diagram of Ti-O compound [10] reported that the rutile is formed at above $800^{\circ} \mathrm{C}$ in most probable to equilibrium conditions. Therefore, only the anatase phase is obtained since the covered range $325-475^{\circ} \mathrm{C}$ of substrate temperature, is still insufficient to grow rutile phase. The mean crystallite size has been obtained with Scherer relation [11],

$$
\mathrm{D}=\mathrm{k} \lambda /(\beta \operatorname{Cos} \theta)
$$


where $\mathrm{D}$ is the crystallite size, $\mathrm{k}$ is a fixed number of $0.9, \lambda$ is the $\mathrm{X}$-ray wavelength, $\theta$ is the Bragg's angle in degrees, and $\beta$ is the full-width-at-halfmaximum (FWHM) of the chosen peak, and equal to $\mathrm{B}_{\text {sample }}-\mathrm{B}_{\text {instrument, }}$ where $\mathrm{B}$ is the broadening. The instrumental broadening was done using the free strain quartz sample delivered by Diano Corporation by using the same condition conducted for the experiment. Using FWHM values of the (101) reflection, the values for representative investigated samples, are given in Table (1). The crystallite size increases from 17 to $21 \mathrm{~nm}$ at $375^{\circ} \mathrm{C}$ up to $475^{\circ} \mathrm{C}$, respectively.

Table (1): Values of crystallite size

\begin{tabular}{|c|c|}
\hline Temperature $\left({ }^{\circ} \mathrm{C}\right)$ & Crystallite size $(\mathrm{nm})$ \\
\hline 375 & 17 \\
\hline 425 & 19 \\
\hline 475 & 21 \\
\hline
\end{tabular}

Atomic Force Microscopy (AFM) images from samples prepared at 375, 425 and $475^{\circ} \mathrm{C}$ and deposition time 30 minutes are reported in Fig.(3). It shows that the films are composed of small crystallites. The average crystallite diameters are 20, 23 and $28 \mathrm{~nm}$, respectively. These values are larger than the size measured with XRD. As XRD is sensitive to the crystallite thickness perpendicular to the film and the AFM image show the film surface, therefore, the grains are larger at the film surface than that at the inner regions.

\subsection{Electrical Properties}

The undoped $\mathrm{TiO}_{2}$ consists of non-stoichiometric $\mathrm{TiO}_{2}$, which contains bulk oxygen vacancies and interstitial oxygen ions, that act as donor states. These states permit the adsorption of oxygen. When oxygen molecule gets adsorbed at the $\mathrm{TiO}_{2}$ film surface or at the grain boundaries, it extracts electrons from the conduction band, thus, reducing the concentration of the electrons which allowing an increase in the film resistivity [8]. As adsorbed oxygen concentration increases, the number of conduction band electrons decreases further and the $\mathrm{TiO}_{2}$ film become more resistive [12].

It is found that [13] when $\mathrm{TiO}_{2}$ film, prepared by sputtering technique on fused quartz substrates, exposed to heating-cooling thermal cycles in air and vacuum between 25 and $400^{\circ} \mathrm{C}$, the film resistivity at room temperature is increased after the cycling in air and is decreased after cycling in vacuum. This result had been explained by the oxidation during heating-cooling cycle in air and the reduction in vacuum. Thus, oxidation of the film decreases the number of free carriers whereas reduction increase it. 

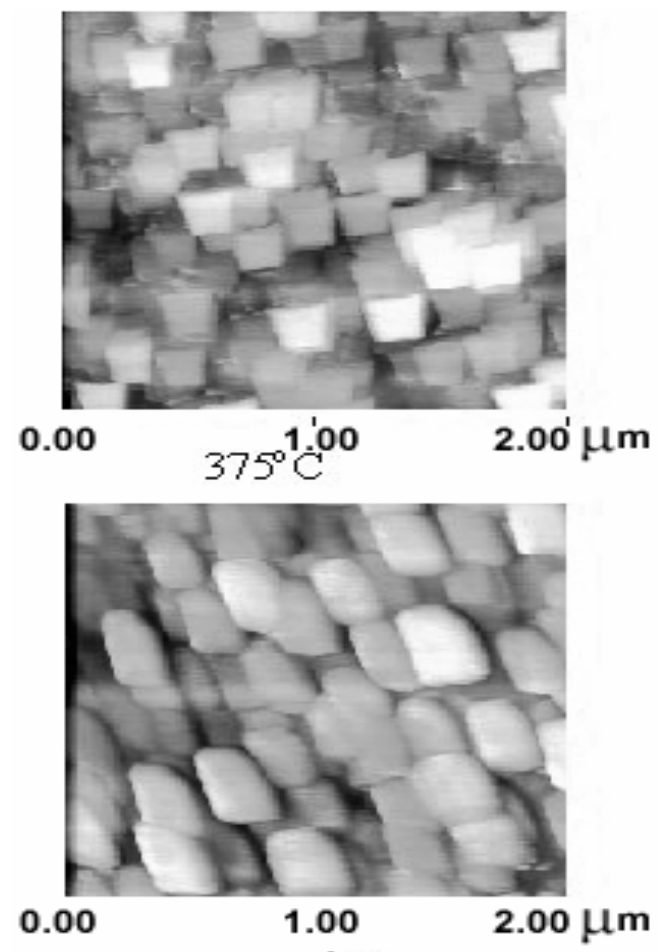

$425^{\circ} \mathrm{C}$

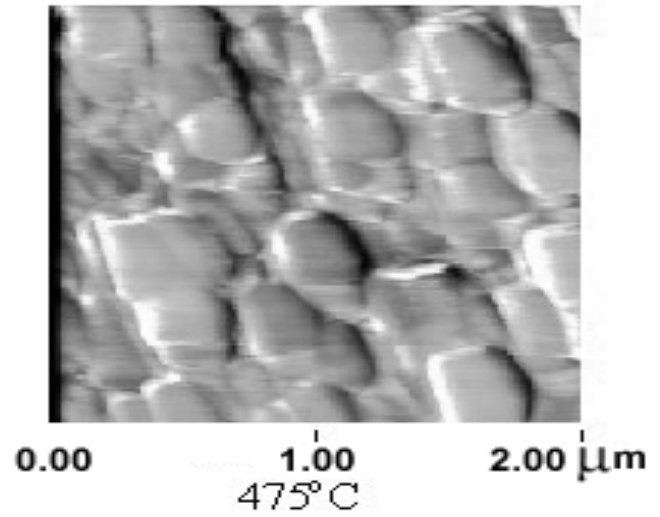

Fig. (3): $\mathrm{AFM}$ images for $\mathrm{Tio}_{2}$ film prepared at $\left(375,425\right.$ and $\left.475^{\circ} \mathrm{C}\right)$ and $30 \mathrm{~min}$.

In this work the dc electrical resistivity versus temperature from 25 up to $400^{\circ} \mathrm{C}$ is studied for $\mathrm{TiO}_{2}$ films deposited at (10 and 30 minutes) and different deposition temperatures at each deposition time. At each test temperature, we wait 10 minutes to attain a constant value of the resistance before recording. A representative curve for the change of the film resistance with the time at constant test temperature is shown in Fig.(4). 


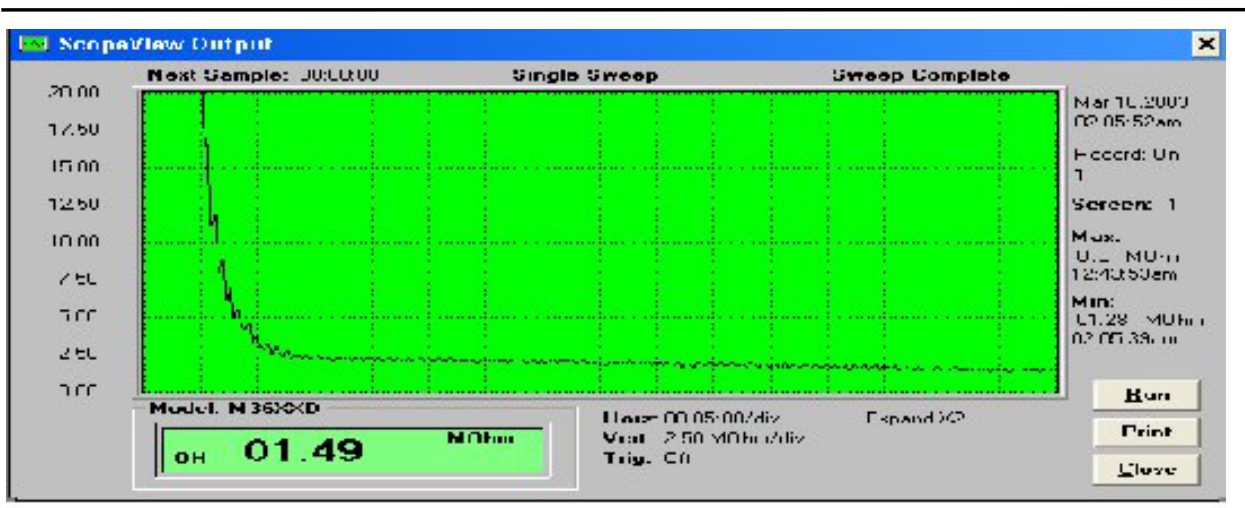

$20 \mathrm{~min}$.

Fig. (4): Effect of time of film resistance at operating temperature $3000^{\circ} \mathrm{C}$ for $\mathrm{TiO}_{2}$ samples deposited at $375^{\circ} \mathrm{C}$ and $20 \mathrm{~min}$.

The recorded data are modified by introducing sample dimensions to calculate the film resistivity and drawn it as a function of test temperature. It is clear from Fig.(5) that all the investigated samples show higher resistance at room temperature $\left(\approx 10^{12} \Omega\right)$ which could not be detected by the recording device (METEX).

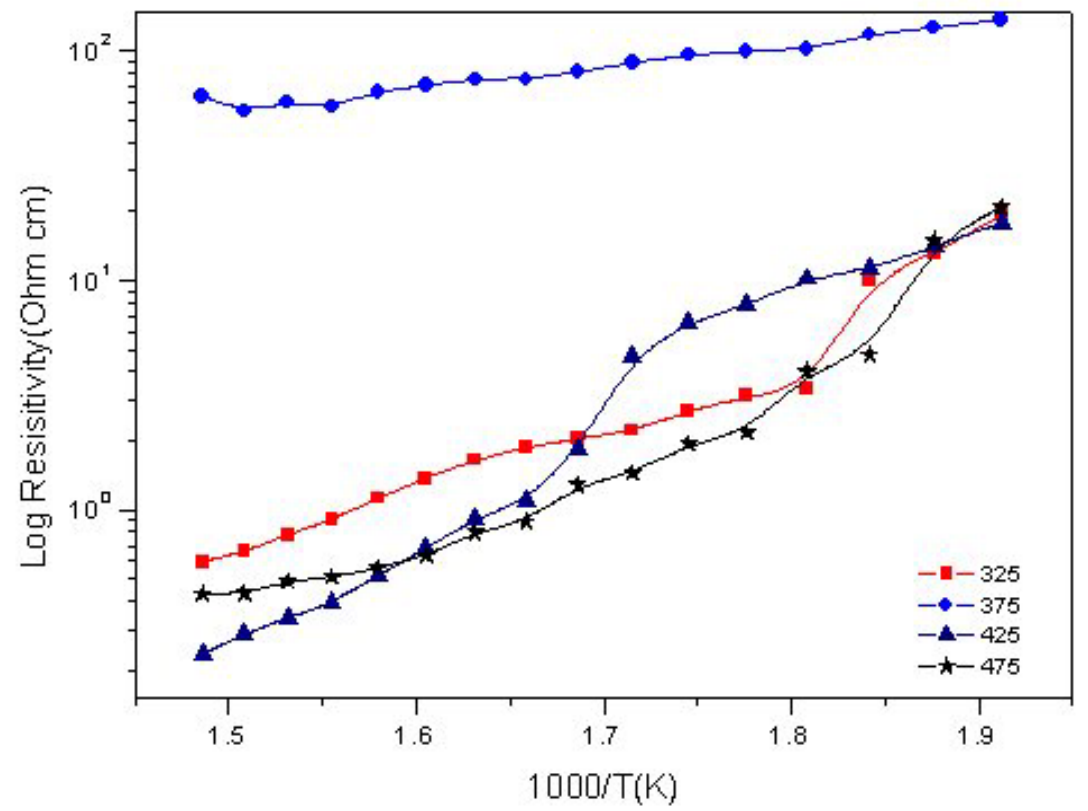

Fig. (5): Resistivity versus $1000 / \mathrm{T}$ (k) for $\mathrm{TiO}_{2}$ films prepared at different deposition temperatures and constant spray time (10 $\mathrm{min})$. 
As the test temperature raised, the film resistance decreased. The $\mathrm{TiO}_{2}$ films deposited at 375,425 and $475^{\circ} \mathrm{C}$ at constant deposition time $(30 \& 10$ min.), show almost the same trend of decreasing the resistivity with increasing the test temperature. The samples prepared at $325^{\circ} \mathrm{C}$ show high resistivity all over the covered temperature range compared with the samples prepared at temperatures higher than $325^{\circ} \mathrm{C}$. This may be due to the structure of the $\mathrm{TiO}_{2}$ films as revealed by their XRD, Fig.(2a).

It is worthy to pay attention that the $\mathrm{TiO}_{2}$ films prepared at $325^{\circ} \mathrm{C}$ show about six order of magnitude lower resistance with raising the temperature from room temperature up to $400^{\circ} \mathrm{C}$, while those samples prepared at deposition temperature higher than 325 show eight order of magnitude $\left(10^{12}\right.$ to $\left.10^{4} \Omega\right)$.

The higher resistivity for the investigated $\mathrm{TiO}_{2}$ films regardless the preparation conditions could be explained as: during film deposition, it is quite likely that large numbers of oxygen molecules are adsorbed in the film both at grains boundaries and on the surface. The adsorbed oxygen will produce potential barriers which hinder the electron transport. Also, the adsorbed oxygen withdraws the electron from the conduction band allowing high resistivity.

The reversible decrease in $\mathrm{TiO}_{2}$ film resistivity with increasing test temperature could be attributed to the evolution of the adsorbed oxygen at film surface and grain boundaries which allow the increase of electrons and decrease of the potential barrier at grain boundaries.

The determined activation energy from the slope in Fig.(5) is found to be $(0.2 \mathrm{eV})$, which is smaller than the activation energy for intrinsic conduction. This make one conceive that adsorbed oxygen evolution by increases the film temperature is the main mechanism for the decrease of film resistivity. The evolution of oxygen from $\mathrm{TiO}_{2}$ film when heated at elevated temperatures is reported in literature [14].

\subsection{Effect of gases on dc electrical properties:}

In this part, $\mathrm{TiO}_{2}$ films deposited at $475^{\circ} \mathrm{C}$ and 30 minutes, since they have well defined crystallite shapes as revealed by AFM, is selected as model to study the effect of reducing $\left(\mathrm{CO} \& \mathrm{H}_{2}\right)$ and oxidizing $\left(\mathrm{O}_{2}\right)$ gases on its dc resistance. This study is devoted to explore to what extent the prepared samples could be used as sensors to these gases.

A home-made measuring system provided with oxygen, hydrogen cylinders with their manometer and $\mathrm{CO}$ glass reactor is used. All these gas 
sources are connected to the system through a polyethelene pipe line $\approx 1.5$ meter and with glass tapes. The results of the change in the film resistance with time of the $\mathrm{TiO}_{2}$ films during their exposure to $\mathrm{CO}, \mathrm{H}_{2}$ and $\mathrm{O}_{2}$ at different operating temperature are shown in Figs. $(6,7,8)$.
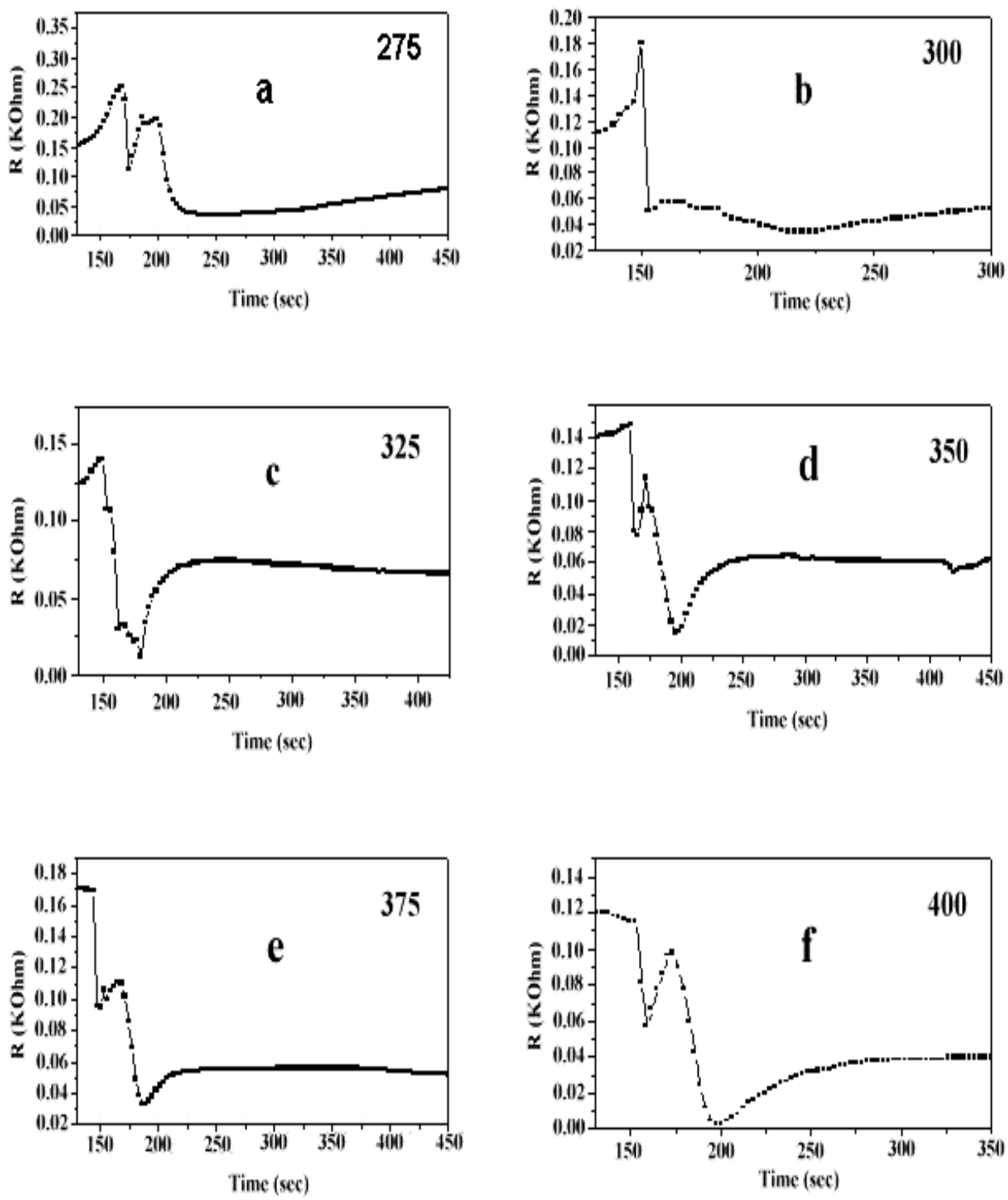

Fig. (6): Effect of $\mathrm{CO}$ gas on the resistance of $\mathrm{TiO}_{2}$ prepared at $375^{\circ} \mathrm{C}$ and 30 main at different operating temperatures. 

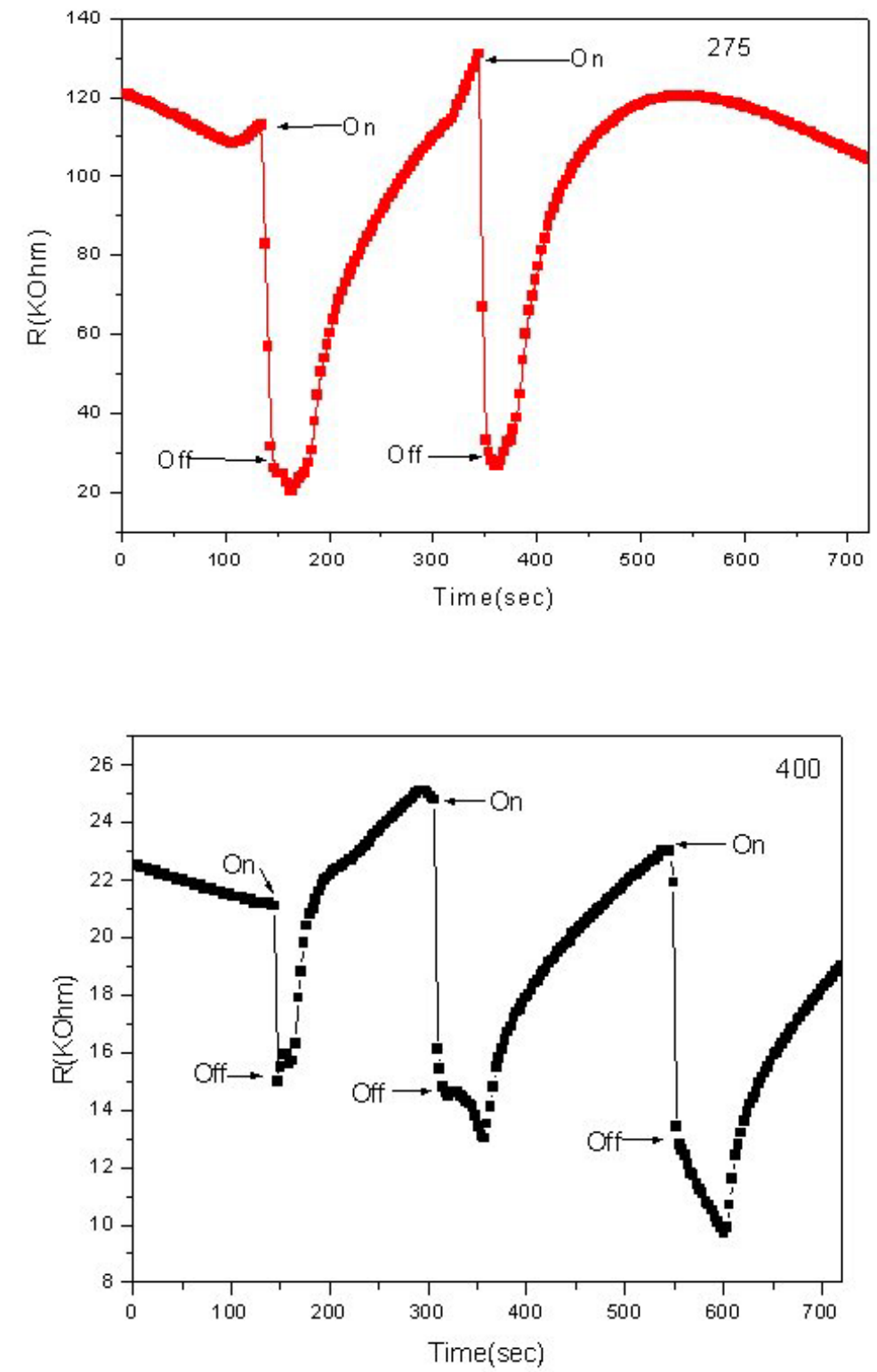

Fig. (7): The dynamic response for $\mathrm{H}_{2}$ at two operating temperatures for $\mathrm{TiO}_{2}$ prepared at $375^{\circ} \mathrm{C}$ and $\min$. 


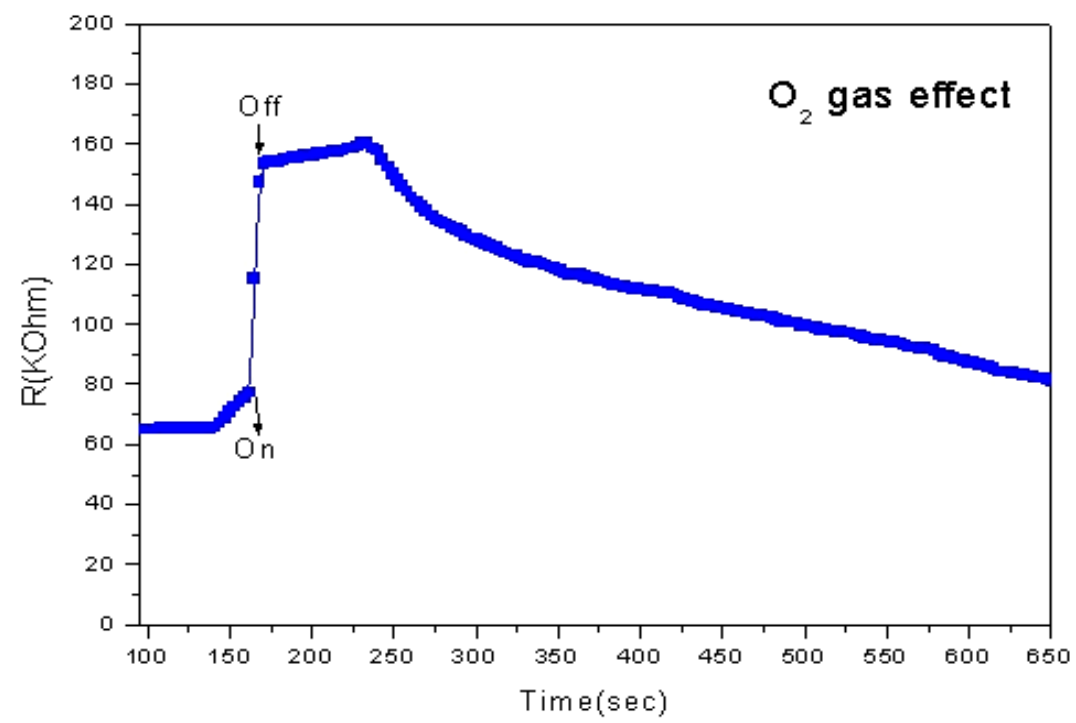

Fig. (8): The dynamic response for $\mathrm{TiO}_{2}$ prepared at $375^{\circ} \mathrm{C}$ and $30 \mathrm{~min}$., the operating temperature is $300^{\circ} \mathrm{C}$.

\subsubsection{Carbon monoxide:}

a) dynamic response

The salient feature for the curve family of $\mathrm{CO}$ is the slight increase of the film resistance at the onset of the curve which decreases as the operating temperature increases. When the gas inlet is opened to the test chamber, it causes slight decrease of the operating temperature allowing the slight increase in the equilibrium resistance at the operating temperature. Since the flow of CO is constant at all operating temperatures, then the induced reduction in the operating temperature due to the gas rushing will decrease as the operating temperature decreases, as shown in Fig.(6).

Also, at higher operating temperatures a sudden decrease in film resistance is followed by a slight increase in film resistance followed by a sudden and continuous decrease in resistance. This is not observed at lower operating temperatures. This observation could be explained, as the operating temperature increases, the thermal flux opposes the gas stream at its entrance inducing little disturbance in the operating temperature causing the increase in film resistance.

Also, the observed slower recovery of the film resistance during the swept time (10 minutes) may be due to the loss of the sharp on-off cycle of the gas. This means that the generation of $\mathrm{CO}$ is strong and fades with time. The tiny residual of $\mathrm{CO}$ gas impede the recovery of the film resistance. 
The sharp instantaneous decrease in the film resistance when exposed to $\mathrm{CO}$ gas could be rendered to the reaction of the $\mathrm{CO}$ gas with the adsorbed oxygen on the film surface and at the grain boundaries releasing the trapped electrons back to the film and increasing its conductivity. The obtained results are consistent with that expected based on concepts [15] and reported data in the literatures [16].

\section{b) Sensitivity and response time}

The sensitivity $\mathrm{S}$ is defined by the form:

$$
\mathrm{S}=\left(\mathrm{R}_{\mathrm{o}}-\mathrm{R}_{\mathrm{gs}}\right) / \mathrm{R}_{\mathrm{gs}}
$$

where $R_{o}$ is the resistance of the sensor before passing the gas and $R_{g s}$ that after passing it. Also, the response time, is defined as the time needed for the sample to reach $90 \%$ of the final signal for a given concentration of the gas.

The crystallite size and the gas concentration are constant while the operating temperature is varied. The sensitivity of the sample is calculated and traced as a function of operating temperature as shown in Fig.(9). The error bars on the graph indicate that the degree of repeatability upon measurements of three fresh $\mathrm{TiO}_{2}$ films prepared at $475^{\circ} \mathrm{C}$ and 30 minutes. The samples show high sensitivity to $\mathrm{CO}$ gas at the vicinity of $310^{\circ} \mathrm{C}$. The response time for $\mathrm{CO}$ at low operating temperature is 3 seconds as shown in Fig.(10).

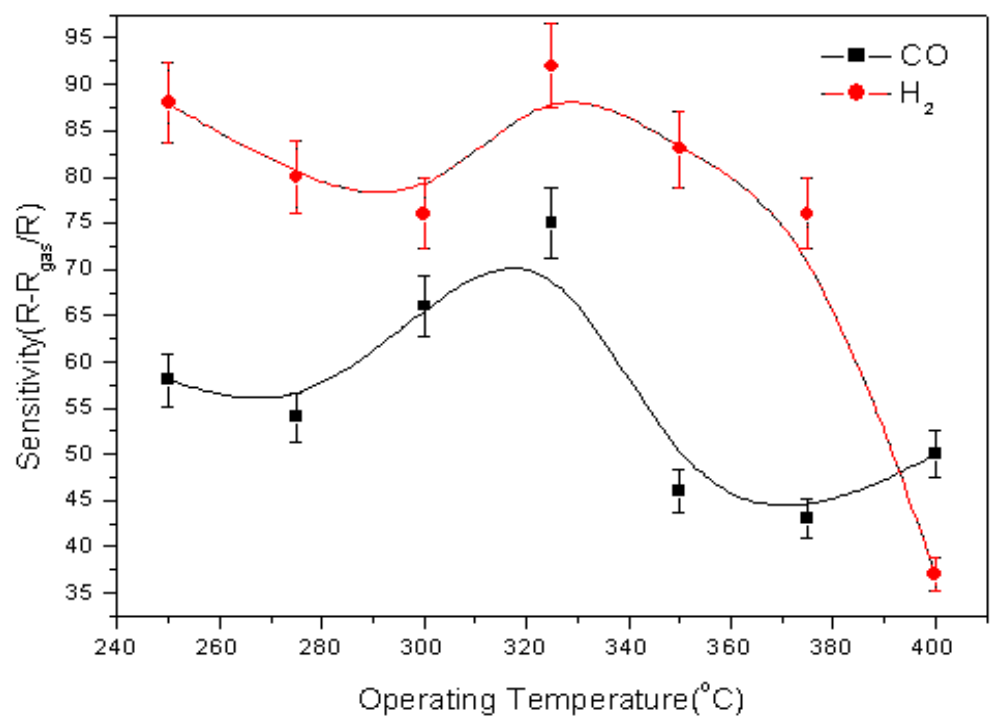

Fig. (9): $\mathrm{TiO}_{2}$ film sensitivity towards $\mathrm{CO}$ and $\mathrm{H}_{2}$ gases at different operating temperatures. 


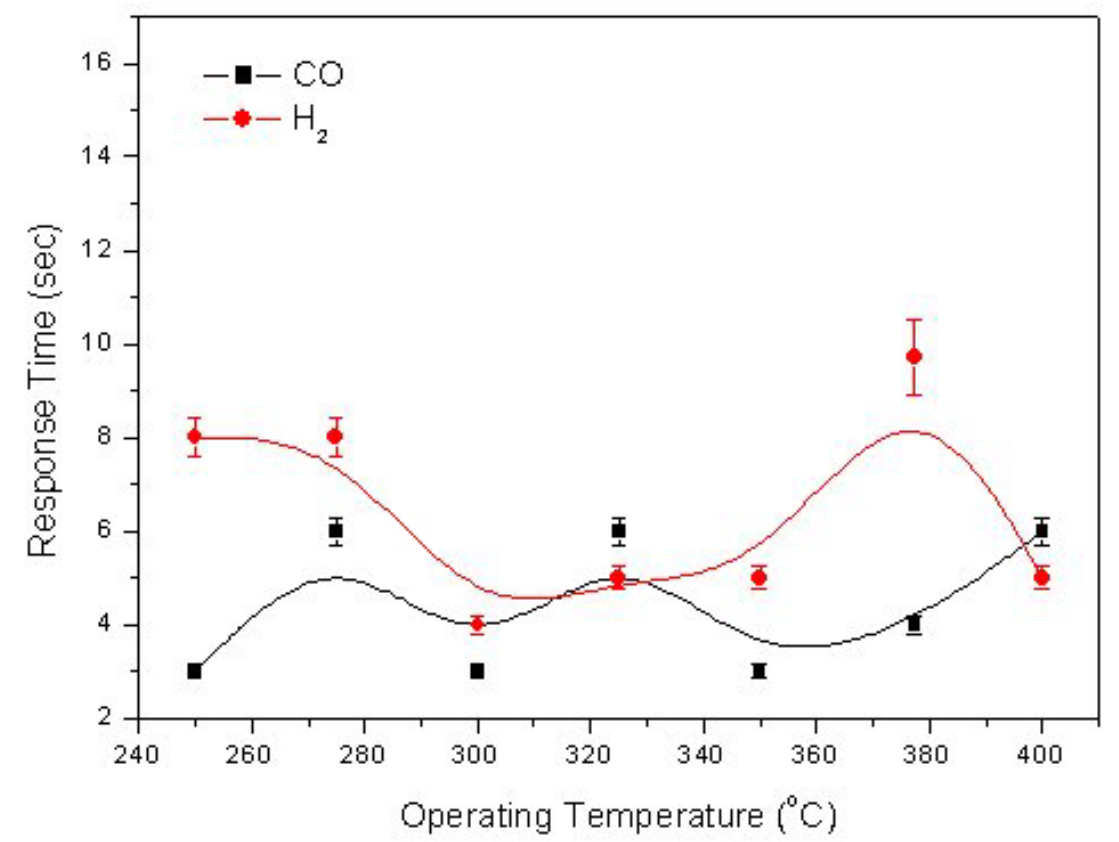

Fig. (8): $\mathrm{TiO}_{2}$ film response time towards $\mathrm{CO}$ and $\mathrm{H}_{2}$ gases at different operating Temperatures.

\subsubsection{Hydrogen and oxygen \\ a) dynamic response}

A representative curve for the sample response for Hydrogen at high and low operating temperatures $\left(400\right.$ and $\left.275^{\circ} \mathrm{C}\right)$ is shown in Fig.(7). The observed slight increase in film resistance at the onset of the curve tending to vanish at higher operating temperatures is mostly as observed in the case of $\mathrm{CO}$ gas sensing. This could be attributed to the slight decrease in the operating temperature, due to rushing of the test gas at the first moments of its entrance, allowing a corresponding slight increase in the film resistance. The (on-off) cycle of the gas is well defined which is not observed in the case of CO gas. The repeatable cycles support the sensing phenomena exerted by the film.

The dynamic response for oxygen gas is shown in Fig.(8). It is clear that the film resistance show sharp increase at the entrance (on) of the oxygen gas, which is not as the $\mathrm{CO}$ and $\mathrm{H}_{2}$ gas, followed by a slow decrease in the film resistance in case of closing the gas (off). The increase in film resistance when exposed to oxygen gas and the decrease of it in case of $\mathrm{CO}$ and $\mathrm{H}_{2}$ support the behaviour of $\mathrm{TiO}_{2}$ as an n-type semiconductor. 
b) Sensitivity and response time

The film sensitivity to sensing and response time for $\mathrm{CO}$ and $\mathrm{H}_{2}$ with different operating temperatures is shown in Fig.(10). The higher sensitivity for $\mathrm{H}_{2}$ is found to be at $330^{\circ} \mathrm{C}$ while for $\mathrm{CO}$ is at $310^{\circ} \mathrm{C}$ (Fig.10). The response time for $\mathrm{CO}$ and $\mathrm{H}_{2}$ is random, but at lower operating temperature, the response time is shorter for $\mathrm{CO}(\sim 3 \mathrm{sec}$. $)$ than that for $\mathrm{H}_{2}(\sim 7 \mathrm{sec}$. $)$.

\section{c) Sensitivity mechanism}

Since the film measurements are conducted in atmospheres almost without oxygen (Nitrogen ambient), the increase in film conductivity can not be due to hydrogen removing oxygen from the lattice $[17,18,19]$ or the removal of chemisorbed oxygen [20,21,22]. It is likely that the hydrogen molecules get dissociated at the defects on the film surface. The molecules can diffuse into the lattice, and act as electron donors [23,24,25]. But this process would lead to very slow response and recovery time and complete recovery would be difficult.

Since, the investigated film almost regains its original resistance with hydrogen cycling; it appears that this is not the dominant mechanism behind hydrogen sensitivity. Hence, we suspect that the probable interaction between the film surface and hydrogen is the chemisorptions of the dissociated hydrogen on the film surface. During chemisorptions, hydrogen acts as a surface state and a partial charge transfer takes place from hydrogen to the conduction band of $\mathrm{TiO}_{2}$ film. This creates an electron increase that enhances the film electrical conductance. On removing the hydrogen (off), electron transfer takes place back to hydrogen and it desorbs, thus, restoring the original resistance of the film.

On exposing the film to oxygen ambient (on), the lattice re-oxidizes takes electrons from the conduction band and, hence, the film conductivity decreases. On removing oxygen (off), the reduction of the lattice will not immediately occur. Therefore, the film requires several hours to restore its original conductivity.

\section{Conclusion:}

In the present work, it has been demonstrated a way to produce nanosized $\mathrm{TiO}_{2}$ films with only anatase phase through spray pyrolysis technique. This technique could be applied to extensive and low-cost production.

Film structure management (amorphous, crystalline and crystallite size) could be achieved by the control of the technique parameter (temperature and time). Qualitative agreement between structural features and electrical response 
is inferred. The film resistance shows drastic and fast response to $\mathrm{CO}, \mathrm{H}_{2}$ and $\mathrm{O}_{2}$. The film sensitivity and response time for each gas is calculated and traced as a function of operating temperature. Many mechanisms are discussed to explain the obtained results. The prepared $\mathrm{TiO}_{2}$ films offer promising perspectives for gas sensing applications.

\section{References}

1. Hong-Ming Lin, Chia-His Keng and Chiun-Yen Tung., Nanostrustured materials, 9, 747 (1997).

2. P. T. Moseley and B.C. Tofield, "Solid State Gas Sensors", Adam Hilger imprint by IOP Publishing Ltd techno House, Redcliff Way Bristol BSI 6NX, England 242 Cherry Street, Philadelphia, PA 19106, USA, 56,126127 (1987).

3. L.D. Birkefeld, A.M. Azad and S.A. Akbar, J. Am. Ceram. Soc., 75, 2961 (1992).

4. J. Hunsko, V. Lantto and H. Torvela, Sens. Actuators B, 16, 245 (1993).

5. Fa-Min Liu and Tian-Min Wang, Applied Surface Science, 195, 284 (2002).

6. K. Zakrzewska, A. Brudnik, M. Radecka and W. Posadowski, Thin Solid Films, 343/344, 152 (1999).

7. D. Wicaksana, A. Kobayashi and A. Kinbara, J. Vac. Sci. Technol., A10, 1479 (1992).

8. L. Castaňeda, J.C. Alonso, A. Ortiz, E. Andrade, J.M. Saniger and J.G. Baňuelos, Materials Chemistry and Physics, 77, 938 (2002).

9. G. San Vicente, A. Morales and M.t. Gutierrez, Thin Solid Films, 391, 133 (2001).

10. R. Roy and W.B. White, J. Cryst. Growth, 13/14, 78 (1972).

11. B.D. Cullity, "Elements of $x$-ray diffraction", Addison-Wesley Publishing Company Inc., London (1978).

12. R.K. Sharma, M.C. Bhatanger and G.L. Sharma, Sensors and Actuators B, 45, 209 (1997).

13. H. Tang, K. Prasad, R. Sanjinès and F. Levy, Sensors and Actuators B, 71, 26 (1995).

14. E. Comini, V. Guidi, C. Frigeri, I. Ricco and G. Sberveglieri, Sensors and Actuators B, 77, 16 (2001).

15. P. T. Moseley, J.O.W. Norris and D. E. Williams, "The techniques and Mechanical In Gas Sensing”, 194 (1991)

16. O.K. Varghese, D. Gong, M. Paulose, K.G. Ong and C.A. Grimes, Sensors and Actuators B, 93, 338 (2003).

17. R.D. Shanonon, J. Appl. Phys., 35, 3414 (1964).

18. K.H. Kim, E.J. Ju and J.S. Choi, J. Phys. Chem. Solid, 45, 1265 (1984). 
19. G.C. Mather, F.M.B. Marques, J.R. Frade, J. Eur. Ceram. Soc., 19, 887 (1999).

20. R.M. Walton, D.J. Dwyer, J.W. Schwank, J.L. Gland, Appl. Surf. Sci., 125, 199 (1998).

21. M.J. Madou, S.R. Morrison, "Chemical Sensing with Solid state Devices", Academic Press, New Yourk, (1989).

22. G.B. Raupp, J.A. Dumesic, J. Phys. Chem., 89, 5240 (1985).

23. L.D. Birkefeld, A.M. Azad, S.A. Akbar, J. Am. Ceram. Soc., 75, 2964 (1992).

24. J.B. Bates, J.C. Wang, R.A. Perkins, Phys. Rev. B, 19, 4130 (1979).

25. G.J. Hill, Br. J. Appl. Phys., 1, 1151 (1968). 